\title{
ISOLATION AND CHARACTERIZATION \\ OF POTENTIAL PROBIOTIC BACTERIA FROM JORDANIAN TRADITIONAL PICKLED AND FERMENTED FOODS
}

\author{
SUHA M. ABUDOLEH ${ }^{1 *}$, SARA O. HAMDAN ${ }^{2}$, ADEL M. MAHASNEH $^{2}$, \\ ZAHIRA M. AL-KHANI ${ }^{3}$, and AHMAD A. TALHOUNI ${ }^{3}$
}

\author{
${ }^{1}$ Department of Basic Pharmaceutical Sciences, Faculty of Pharmacy, Isra University, Jordan \\ ${ }^{2}$ Department of Biological Sciences, Faculty of Sciences, University of Jordan, Jordan \\ ${ }^{3}$ Department of Applied Pharmaceutical Sciences, Faculty of Pharmacy, Isra University, Jordan
}

\begin{abstract}
Locally fermented vegetables and dairy products were tested for the presence of Lactobacillus strains, and their probiotic properties were assessed including survival in gastrointestinal conditions and bile tolerance. Nine Lactobacillus strains were isolated from selected fermented food products local to the Jordanian diet; four strains L. brevis 3, two of L. buchneri, and one each of L. brevis 1, L. fermentum 1, and L. fermentum 2 were identified. All isolates were able to tolerate the acidic simulated gastric juice and alkaline simulated intestinal juice to varying degrees after incubation for three and four hours, respectively, with a reduction in viable counts of ca. 1-2 log colony forming unit per $\mathrm{mL}(\mathrm{CFU} / \mathrm{mL})$. Similar results were observed in four concentrations of bile salts, with the exception of L. brevis 3 and L. buchneri which were not able to survive in $2 \%$ bile salt. The results of this study show that local traditional fermented vegetable and dairy products are good sources of potentially beneficial Lactobacillus probiotic strains. Further studies, including in vivo testing, are required to elucidate the full probiotic capacity of the isolated species.
\end{abstract}

Keywords: Lactobacillus, probiotics, fermented vegetables, dairy.

The therapeutic efficacies and bioactive properties of fermented foods have been of interest for the past few decades. The term "probiotics" has been used to denote any "live microorganism that, when administered in adequate amounts, confers a health benefit on the host" (1). The extensive health benefits of probiotic bacteria largely found in various fermented food products include reducing the risk of type 2 diabetes, heart disease, hypertension, hyperlipidemia, as well as decreased mortality, improved bone density in osteoporosis, and altered mood and brain activity (2).

Lactic acid bacteria (LAB) have been well established as probiotics due to their ability to produce antimicrobial substances against pathogens, tolerance of gastric acidity and bile salts, and adhesion to the intestinal tract, among other characteristics as well (3). Lactobacillus and Bifidobacterium are arguably the two species most associated with probiotic development, especially in dairy and traditionally fermented foods $(4,5)$. Probiotic bacteria with numerous proven health effects were found in local dairy products (6), fermented goat milk cheese(7), and olives (8). Recently, there has been a shift in research away from dairy-based sources of probiotics and towards more traditional, non-dairy fermented foods such as vegetables, fruits, cereals, and meats $(9,10)$.

Pickled and fermented vegetables are a staple in the Jordanian diet. These include pickled chili peppers, fermented herbs, and makdous, traditionally made with eggplant and/or green peppers stuffed with walnuts and garlic and preserved in olive oil (11). Fermented goat milk in the form of jameed and kishk are also widespread local products. The fermentation of these foods is largely dependent on the various indigenous microorganisms naturally occurring on the vegetables and herbs used. In a previous study conducted in Jordan, camel's milk was shown to have various Lactobacillus species with probiotic properties (12).

With the growing body of evidence supporting the interrelationship between probiotics and health, more attention has been given to studying the effect of indigenous LAB present in local and regional

* Corresponding author: e-mail: suha.abudoleh@iu.edu.jo 
fermented food products as a novel source of probiotics $(13,14)$. The aim of this research is to study Lactobacillus strains isolated from traditional fermented Jordanian foods and to assess their characteristics as probiotics.

\section{MATERIALS AND METHODS}

\section{Collection of fermented food samples}

The foods used as potential sources for probiotic bacteria include plain pickled green hot chili peppers, pickled chili peppers and garlic in olive oil, pickled chili peppers in yogurt, pickled herbs and garlic, pickled green olives salad, eggplant makdous, pickled mixed vegetables, homemade yogurt, jameed, and kishk. The fermented products chosen for this study were all homemade except the pickled mixed vegetable, which was purchased from a local Jordanian market. Each food sample was given a code.

\section{Bacterial growth enrichment}

The method used was based on that of Mahasneh and Hamdan(14) with modifications. Each food product was homogenized, and a $1 \mathrm{~mL}$ sample was added to $10 \mathrm{~mL}$ of sterile de Man, Rogosa and Sharpe broth (MRS) (Oxoid, UK) and incubated anaerobically at $37^{\circ} \mathrm{C}$ for 5 days using anaerogen bags (AnaeroGen, UK).

\section{Isolation of potential probiotic species}

Enriched samples were serially diluted using sterile $\mathrm{NaCl}$ solution $(0.9 \%)$. One hundred $\mu \mathrm{l}$ aliquots from each dilution were plated onto MRS agar (Oxoid, UK) supplemented with $0.01 \%$ bromocresol purple. Inoculated plates were incubated anaerobically at $37^{\circ} \mathrm{C}$ for 24 hours. Potential LAB was identified by the presence of a yellow halo around single bacterial colonies. Each isolated colony was subcultured thrice to ensure isolate purity.

\section{Identification of bacterial strains \\ General characterization of the isolates}

Catalase and oxidase activity, Gram stain reaction, spore formation, and DNase activity and hemolysis were all used for basic characterization of the isolated bacterial colonies.

\subsubsection{Species identification using API 50}

The API $50 \mathrm{CH}$ kits and CHL media (BioMèrieux, France) were used based on the manufacturers' instructions to test the isolated bacteria for acid production from carbohydrates and related compounds. Results were recorded after incubation at $37^{\circ} \mathrm{C}$ for 24 and 48 hours. The apiweb ${ }^{\mathrm{TM}}$ identification software with a database (V5.1) was used to analyze the results.

\section{Bacterial preservation}

Bacterial strains that have been isolated, characterized, and identified were maintained in MRS broth (Oxoid, UK) supplemented with 30\% glycerol and stored at $-20^{\circ} \mathrm{C}$.

\section{Simulated gastric and intestinal juices preparation}

The gastrointestinal simulation was based on the method used by Mahasneh and Hamdan (14). Fresh juices were prepared daily. For gastric juice simulation, 0.3\% w/v pepsin (P7000-25G SigmaAldrich, USA) was suspended in sterile $0.5 \% \mathrm{w} / \mathrm{v}$ $\mathrm{NaCl}$ solution. The $\mathrm{pH}$ was set to 3.0 using $1 \mathrm{M}$ $\mathrm{HCl}$ and measured with a $\mathrm{pH}$ meter. For the intestinal juice simulation, $0.1 \%$ pancreatin USP (P-1500, Sigma-Aldrich, USA) was also suspended in sterile $0.5 \% \mathrm{w} / \mathrm{v} \mathrm{NaCl}$ solution, and the $\mathrm{pH}$ adjusted to 8.0 using $0.1 \mathrm{M} \mathrm{NaOH}$.

\section{Simulated gastric juice tolerance by isolated strains}

Each test isolate was grown overnight in MRS broth, followed by resuspension in $\mathrm{K}_{2} \mathrm{HPO}_{4}$ (maintained at $\mathrm{pH} 6.5$ ) at a concentration of $0.5 \mathrm{McFarland}$. The suspension was centrifuged at $4500 \mathrm{rpm}$ for 20 minutes, the collected pellet was washed twice in $50 \mathrm{mM} \mathrm{K}_{2} \mathrm{HPO}_{4}$, and the final pellet was resuspended in $3 \mathrm{~mL}$ of the same buffer. From this suspension for each isolate, a $1 \mathrm{~mL}$ aliquot was centrifuged at $4500 \mathrm{rpm}$ for 20 minutes, the pellet of which was resuspended in $9 \mathrm{~mL}$ of simulated gastric solution and incubated for 3 hours at $37^{\circ} \mathrm{C}$. Total viable counts on MRS agar were recorded before and after the incubation period.

\section{Simulated intestinal juice tolerance by isolated strains}

After the 3 hour incubation period in the simulated gastric juice, $1 \mathrm{~mL}$ from each isolate tube was transferred to $9 \mathrm{~mL}$ of simulated intestinal juice and incubated for four hours at $37^{\circ} \mathrm{C}$. Total viable counts have also recorded on MRS agar after the incubation period was complete.

\section{Viable count determination}

The spread plate method on MRS agar was used to determine the viable count for the simulated gastric and intestinal juices tolerance test. The inoculated simulated juice(s) were serially diluted using sterile $0.9 \% \mathrm{NaCl}$ solution. One hundred $\mu \mathrm{l}$ from each 
dilution was spread onto MRS plates in triplicates, followed by anaerobic incubation at $37^{\circ} \mathrm{C}$ for 48 hours.

\section{Bile tolerance test}

MRS broth supplemented with $0.3,0.5,1$, and $2 \%(\mathrm{w} / \mathrm{v})$ ox gall (Oxoid, UK) was used to test the bile tolerance of the bacterial isolates. The four concentrations of bile solution were prepared, distributed into tubes with a final volume of $10 \mathrm{~mL}$, and sterilized by autoclaving $\left(121^{\circ} \mathrm{C}, 15\right.$ minutes $)$. The isolates were first prepared by growing them overnight in MRS broth at $37^{\circ} \mathrm{C}$, and the following day adjusting the final bacterial concentration to $0.5 \mathrm{McFarland}$, $200 \mu \mathrm{L}$ of which were inoculated into each of the four concentrations of the cooled bile solutions. The total viable count was determined after zero and 24 hours of incubation in the bile solution by taking $1 \mathrm{~mL}$ from each inoculated bile solution, serially diluting it in sterile $0.9 \% \mathrm{NaCl}$, and spreading $100 \mu \mathrm{L}$ of each dilution onto MRS agar plates in triplicates.

\section{Statistical analysis}

The total viable count obtained from the gastric simulation experiment was reported as mean + standard deviation (SD) and was analyzed using one-way analysis of variance (ANOVA) followed by Bonferroni's post-hoc test. For the bile tolerance experiment, data were expressed as means \pm SD and were analyzed using Student's t-test. Differences were considered significant when $\mathrm{p}<0.05$. The data were analyzed using Graph Pad Prism software version (8.0.1). ${ }^{*} \mathrm{p}<0.05,{ }^{* *} \mathrm{p}<0.01,{ }^{* * *} \mathrm{p}<0.001$, ${ }^{* * * *} \mathrm{p}<0.0001$ significant when compared to the zero time of each concentration for the same isolate.

\section{RESULTS AND DISCUSSION}

\section{Isolation and general characterization of LAB isolates}

From all the chosen food sources, potential probiotic candidates were isolated from pickled mixed vegetables, plain pickled green hot chili peppers, jameed, and kishk only. A total of nine LAB isolates were successfully obtained and given codes (Table 1). All isolates had the following characteristics: Gram-positive rods, negative for catalase, oxidase, DNase and gelatinase, non-hemolytic, and no spore-forming ability.

\section{API CH 50 identification}

The nine characterized LABs were identified using API CH 50. They were all found to be Lactobacillus species (Table 2).

\section{Simulated gastrointestinal juice(s) tolerance}

Survival of probiotic bacteria in the harsh conditions of the gastrointestinal tract is necessary for the ability to exert beneficial effects (15). The viable counts of the nine isolates tested before exposure to simulated gastric juice and after three hours incubation in simulated gastric juice followed by four hours incubation in simulated intestinal juice are shown in Table 3 . All the isolates were highly tolerant to gastric juice with no significant differences $(p<0.05$, $0.01,0.001,0.0001)$ after 3 hours of incubation, except V2 isolate where the difference in the viable count was highly significant in comparison with zero time. Additionally, all isolates, except V2 L. brevis 1 , showed a decrease in the viable count after the total 7 hours of incubation of approximately $1-2 \log \mathrm{CFU} / \mathrm{mL}$.

Table 1. Food sources and code names of the chosen nine isolates.

\begin{tabular}{|c|c|}
\hline Food source & Code name \\
\hline \multirow{2}{*}{ Pickled mixed vegetables } & V1 \\
& V2 \\
V3 \\
\hline \multirow{2}{*}{ Plain pickled green hot chili peppers } & G1 \\
& G2 \\
\hline \multirow{2}{*}{ Jameed } & J1 \\
& J2 \\
\hline \multirow{2}{*}{ Kishk } & K1 \\
& K2 \\
\hline
\end{tabular}

Table 2. API CH 50 biochemical identification of potential probiotic strains.

\begin{tabular}{|c|c|c|}
\hline Isolate code name & Identification & API identification percentage \\
\hline V1 & L. brevis 3 & $99.2 \%$ \\
V2 & L. brevis 1 & $99.9 \%$ \\
V3 & L. buchneri & $98.7 \%$ \\
G1 & L. buchneri & $95.1 \%$ \\
G2 & L. fermentum 1 & $89.3 \%$ \\
J1 & L. brevis 3 & $98.4 \%$ \\
J2 & L. fermentum 2 & $56.7 \%$ \\
K1 & L. brevis 3 & $97.0 \%$ \\
K2 & L. brevis 3 & $99.6 \%$ \\
\hline
\end{tabular}


Table 3. Mean total viable count of Lactobacillus isolates after incubation in simulated gastrointestinal juices.

\begin{tabular}{|c|c|c|c|}
\hline \multirow{2}{*}{ Isolate code name } & \multicolumn{3}{|c|}{ Total viable count (mean log CFU/mL + SD) } \\
\cline { 2 - 4 } & \multicolumn{2}{|c|}{ In simulated gastric juice } & In simulated intestinal juice \\
\cline { 2 - 4 } & At zero time & After 3 hours & After 4 hours \\
\hline V1 & $6.83+0.47$ & $6.55+0.06$ & $5.58+0.18^{* *}$ \\
\hline V2 & $8.93+0.41$ & $4.35+0.21^{* * * *}$ & $2.82+0.01^{* * * *}$ \\
\hline V3 & $7.87+0.33$ & $7.46+0.16$ & $5.69+0.81^{* *}$ \\
\hline G1 & $7.53+0.24$ & $7.07+0.5$ & $6.16+0.13^{* *}$ \\
\hline G2 & $7.22+0.31$ & $6.91+0.34$ & $6.2+0.16^{* *}$ \\
\hline J1 & $6.81+0.25$ & $6.19+0.15$ & $5.79+1.07$ \\
\hline J2 & $7.61+0.47$ & $7.57+0.05$ & $6.5+0.31^{*}$ \\
\hline K1 & $7.73+0.24$ & $7.53+0.2$ & $6.78+0.27^{* *}$ \\
\hline K2 & $7.96+0.31$ & $7.62+0.21$ & $6.44+0.19^{* * *}$ \\
\hline
\end{tabular}

L. fermentum 1 (G2) and L. brevis 3 (J1 and K1) showed the highest tolerance to the simulated gastrointestinal conditions. No significant difference was detected between the zero time of $\mathrm{J} 1$ isolate and the whole 7 hours of gastric incubation $(\mathrm{p}<0.05,0.01$, 0.001, 0.0001). Previous studies that isolated L. brevis from fermented kimchi and L. fermentum from mozzarella cheese showed similar resistance of these species to the harsh conditions of the stomach and intestines $(16,17)$.

\section{Bile salt tolerance}

The nine isolates showed variable levels of tolerance against the four different bile salt percentages after 24 hours of incubation. All isolates were able to tolerate $0.3 \%$ bile salt with $0-1 \log \mathrm{CFU} / \mathrm{mL}$ reduction with no significant difference in comparison with zero time in viable count except V2 L. brevis $1(\mathrm{p}<0.05)$ and V3 L. buchneri, $(\mathrm{p}<0.001)$ and G2 L. fermentum $1(\mathrm{p}<0.01)$ these isolates showed the most significant reduction in comparison with zero time viable count.

As the bile salt percentage increased, the mean $\log \mathrm{CFU} / \mathrm{mL}$ decreased by $0-2$ with an average reduction of $1.16 \log \mathrm{CFU} / \mathrm{mL}$, except for V2 L. brevis 1 , which again showed the highest reduction in the viable count. At the highest bile salt concentration, V1 L. brevis 3, V3 L. buchneri, and K2 L. brevis 3 lost viability completely after 24 hours, whereas G1 L. buchneri had the least reduction in the viable count at $2 \%$ bile salt percentage even though the reduction was significantly different from the zero time with $(\mathrm{p}<0.001)$. Overall, the strain that showed the most favorable growth in all the bile salt percentages tested was $\mathrm{J} 2$ L. fermentum 2 where the significant reduction in the viable count was detected only at the $2 \%$ concentration of bile $(\mathrm{p}<0.001)$.
Lactobacilli, such as L. plantarum WCSF1, have shown the ability to survive in the intestinal environment due to their bile salt hydrolase activity, which enables them to deconjugate glycine or taurine from bile salt (18). This can ultimately lead to lower blood cholesterol levels, which has been shown to be one of the health benefits of probiotic bacteria (19). Twenty-seven strains of $L$. plantarum isolated from cheese showed low to moderate tolerance to $0.3,0.5$, and $1 \%$ bile (20). Hypercholesterolemic mice fed $L$. fermentum for seven weeks showed both a decrease in total and low-density lipoprotein cholesterol levels, as well as an increase in high-density lipoprotein cholesterol (21). The high bile salt tolerance demonstrated by this species in our studies may indicate cholesterol-lowering potentials.

Nowadays, probiotics represent an expanding research area. A Medline search of the term probiotics illustrates the significant increase in research undertaken in this field during the past 5 years; over 1000 publications are cited, compared to 85 for the previous 25 years. While this demonstrates the potential significance of this emerging field, much remains to be done to standardize the meaning of the term probiotic and which strains to fulfill the criteria of true probiotic microorganisms (22). The clinical application and the importance of probiotics regarding gut diseases and the immune system increased widely. Probiotics may exert a beneficial effect on Crohn's disease-affected patients who have shown gut microbiota antigens and altered wall permeability. Moreover, some probiotic formulations seem to enhance the therapy for Helicobacter pylori reducing its pathogenic potential. Intestinal ecology imbalance has been also linked to cancer induction, allergy, skin, and urogenital diseases (23). The number of research that focused on the isolation of probiotics 
from fermented food in Jordan is limited, except the study of Mahasneh et al., 2015 in which they successfully isolated 17 Lactobacillus strains with potential probiotics properties from Jordanian traditional fermented vegetables, which indicates that these fermented vegetables can serve as a good source for probiotic isolation.

Unfortunately, many probiotic products have not been properly identified; the identification should not be limited to species level, it must be expanded to the strain level where the characteristics of the probiotic bacteria are strain-specific. The strain identification of the isolated bacteria requires genomic analysis, followed by good documentation and manufactured under good manufacturing practices, or proven clinically, yet various companies make claims that lead consumers and caregivers to believe that they are using reliable products. Thus, the establishment of standards and guidelines represents a necessary first step in making sure that probiotic products are indeed legitimate and effective (22).

\section{CONCLUSION}

The growing body of evidence supporting the presence and beneficial effects of probiotic bacteria in fermented foods, of both dairy and non-dairy origins, has compelled researchers to study traditional local food products for their probiotic properties. The health benefits from such food items may encourage their re-introduction into the human diet at an age where the consumption of processed fast food is growing at an accelerating rate. The results of this study highly support the isolation of probiotics from natural food sources such as fermented food products. Most of the isolated Lactobacillus strains have the potential to be used as market-approved probiotics when the full probiotic criteria are determined. Finally, this study highlights the importance of using homemade food products as a source for probiotic isolation.

\section{Source of funding}

The study was generously funded by the Faculty of Pharmacy at Isra University in Amman, Jordan.

\section{Conflicts of interest}

The authors declare that there are no conflicts of interest.

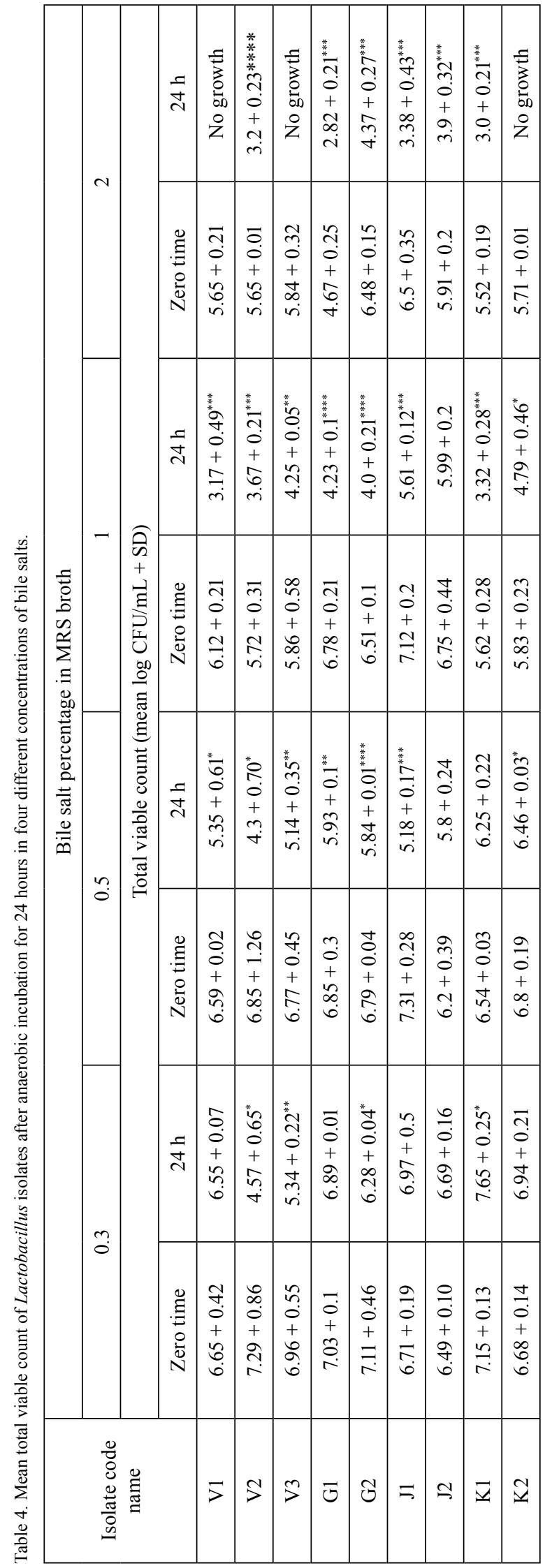




\section{REFERENCES}

1. Hill C., Guarner F., Reid G., Gibson G.R., Merenstein D.J., et al.: Nat. Rev. Gastroenterol. Hepatol. 11, 506 (2014).

2. Marco M.L., Heeney D., Binda S., Cifelli C.J., Cotter P.D., et al.: Curr. Opin. Biotechnol. 44, 94 (2017).

3. Tulini F.L., Winkelstroter L.K., De Martinis E.C.P: Anaerobe 22, 57 (2013).

4. Rivera-Espinoza Y., Gallardo-Navarro Y.: Food Microbiol. 27, 1 (2010).

5. Granato D., Branco G.F., Nazzaro F., Cruz A.G., Faria J.A.F.: Compr. Rev. Food Sci. 9, 292 (2010).

6. Tham C.S.C., Peh K.K., Bhat R., Liong M.T.: Ann. Microbiol. 62, 1079 (2012).

7. Lavilla-Lerma L., Perez-Pulido R., MartinezBueno M., Maqueda M., Valdivia E.: Int. J. Food Microbiol. 136, 136 (2013).

8. Argyri A.A., Zoumpopoulou G., Karatzas K.G., Tsaka-Lidou E., Nychas G.J., et al.: Food Microbiol. 33, 282 (2013).

9. Sanchez B., Ruiz L., Gueimonde M., RausMadiedo P., Margolles A.: Trends Food Sci. Tech. 26, 56 (2012).

10. Min M., Bunt C.R., Mason S.L., Hussain M.A.: Crit. Rev. Food Sci. Nutr. 59, 2626 (2018).

11. Hamady M.L.: Pickled Eggplants In Lebanese Mountain Cookery. pp. 81-83, David R. Godrine Publisher Inc., Jaffrey, New Hampshire 2003.
12. Abbas M.M., Mahasneh A.M.: Afr. J. Microbiol. Res. 8, 1645 (2014).

13. Pisano M.B., Viale S., Conti S., Fadda M.E., Deplano M., et al.: Biomed. Res. Int. 2014, 9 pages 2014.

14. Mahasneh A.M., Hamdan S.O., Mahasneh S.A.: JJBS 8, 81 (2015).

15. Begley M., Gahan C.G., Hill C.: FEMS Microbiol. Rev. 29, 625 (2005).

16. Jang H.J., Lee N.K., Paik H.D.: Food Sci. Biotechnol. 28, 1521 (2019).

17. de Souza B.M.S., Borgonovi T.F., Casarotti S.N., Todorov S.D., Penna A.L.B.: Probiotics Antimicrob. Proteins 11, 382 (2019).

18. Lambert J.M., Bongers R.S., de Vos W.M., Kleerebezem M.: Appl. Environ. Microbiol. 74, 4719 (2008).

19. Begley M., Hill C., Gahan C.G.: Appl. Environ. Microbiol. 72, 1729 (2006).

20. Zago M., Fornasari M.E., Carminati D., Burns P., Suarez V., et al.: Food Microbiol. 28, 1033 (2011).

21. Lye H.S., Kato T., Low W.Y., Taylor T.D., Prakash T., et al.: J. Biotechnol. 262, 75 (2017).

22. Reid G., Jass J., Sebulsky M.T., McCormick J.K.: Clin. Microbiol. Rev. 16, 4 (2003).

23. Lannitti T., Palmieri B.: Clin. Nutr 29, 6 (2010). 